\title{
PR18 (ras-12CYS) Peptide
}

National Cancer Institute

\section{Source}

National Cancer Institute. PR18 (ras-12CYS) Peptide. NCI Thesaurus. Code C29331.

A synthetic form of the ras peptide containing a point mutation at position 12 (glycine to

cysteine). Vaccines using mutant ras peptides may be used in the immunotherapy of various cancers that express ras mutations. ( $\mathrm{NCIO4)}$ 